\title{
Reportagem
}

\section{Uma conversa sobre liderança}

\author{
Por Clandia Asazu
}

Nada de mesas redondas, palestras em série ou apresentações em power point. Formados em um círculo, 73 dirigentes de 16 países reuniram-se para discutir o tema "Qual a liderança que eu preciso para favorecer o aprendizado, a inovação e a cooperação no serviço público?”, no fórum "Aprender, inovar e cooperar: uma conversa entre pares", organizado pela ENAP e pela Canada School of Public Service (CSPS).

"Teremos um pouco de caos para sairmos da rotina", avisava a facilitadora canadense, Diane Gibeault. E o "caos" é bem vindo na metodologia utilizada no fórum, o Open Space Tecnology (OST, Tecnologia do Espaço Aberto), que busca combinar a sinergia e a naturalidade que

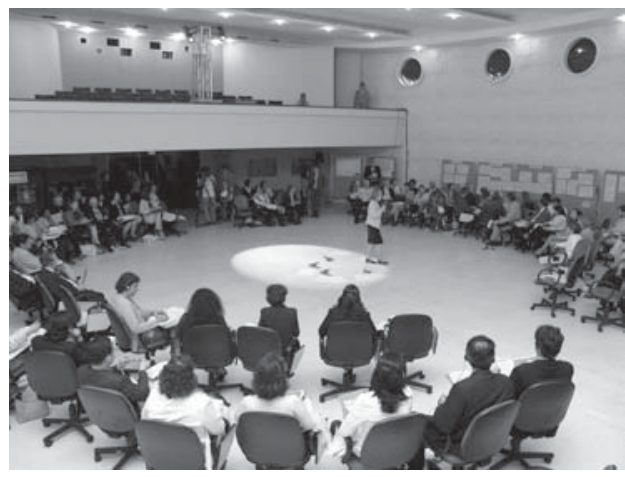

surgem nos bate-papos de coffee breaks para gerar os resultados substantivos de uma boa reunião.

Não se trata, porém, de um brainstorming em grande escala, mas de procurar fazer com que as pessoas falem de forma mais franca possível e engajá-las de modo que elas se sintam parte da solução.

A tônica do encontro internacional foi dada já na abertura do evento pelas duas presidentes das escolas organizadoras: "Se não formos uma organização que aprende, não vamos sobreviver neste mundo", disse Ruth Dantzer, da CSPS. "Formar líderes que valorizem a profissionalização de seus servidores é pré-condição para consolidação de um Estado eficiente", afirmou Helena Kerr do Amaral, da ENAP.

Os próprios participantes, seguindo a metodologia do OST, criaram a agenda, propondo os tópicos para discussões e um horário de encontro. Desse exercício, surgiram 19 tópicos, que variaram de "Que tipo de programas de aprendizado criam a liderança necessária para que o serviço público aprenda, inove e coopere" a "Educação a distância, conexões estratégicas", passando por "Construção de consenso entre instituições em rede" e "Fazer acontecer: a disciplina da execução".

Definida essa etapa, os dirigentes se reuniram em grupos de 5 a 25 pessoas. Participar deste ou daquele grupo e permanecer por mais ou menos tempo nas discussões eram escolhas de cada um. "A idéia é conferir liberdade para que as pessoas compareçam ao encontro em seu melhor estado de espírito, quando 
estão mais produtivas. As escolhas são pessoais o tempo todo, para que elas estejam no seu melhor momento", explica Diane.

Os dois dias de atividades em ambiente multicultural resultaram em questionamentos, reflexões, sugestões e propostas de ações, sumarizadas no relatório de discussão, cujos trechos a RSP reproduz ao longo desta reportagem.

Tópico: Encorajando pessoas a serem criativas no trabalho

"Burocracias não encorajam a criatividade, mas a obediência, a obediência, a obediência. Há um mito de que, no serviço público, a criatividade morre."

"Pessoas consideradas criativas são, muitas vezes, desencorajadas a pensarem em uma carreira no serviço público."

"Algumas organizações adotam o 'fazer de conta' para estimular a criatividade, disponibilizando 'caixas de sugestões criativas', para as quais as pessoas são chamadas a contribuir. No entanto, muitas vezes, as idéias vão direito ao lixo! Como reagir contra esse tipo de comportamento superficial no topo da organização?”

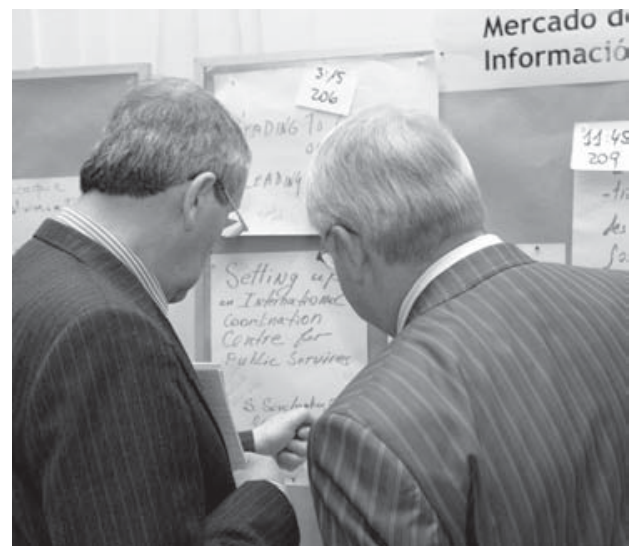

O mercado: as informações eram afixadas em painéis
Tópico: Estratégias inovadoras de aprendizagem

"Como transformar nossas organizações públicas em organizações que querem aprender, sem 'agredir' as pessoas e minimizando as resistências? É preciso trabalhar as pessoas para mudar as atitudes."

"Como mudar a relação professoraluno/servidor de forma a respeitar o saber, a trajetória e a experiência de cada um?"

Tópico: Qual o tipo de liderança é necessário para criar um serviço público que aprende, inova e coopera?

"Líderes devem ser capazes de compartilhar, com sua equipe, a recompensa e a glória e não apenas os sacrifícios. É preciso incluir as pessoas em todos os sentidos."

"É preciso cuidado para não idealizarmos a liderança. Líderes muitas vezes são líderes porque ocupam posições de poder, o que não significa que eles sejam reais ou bons líderes."

"Alguns são bons técnicos e deveriam continuar sendo bons técnicos. Não deveriam ser chamados a serem líderes."

Tópico: Construção de consenso entre instituiçoes em rede

"Como garantir a continuidade de uma iniciativa de rede? Algumas estratégias são: criar um núcleo dinamizador; ter um elo temático; utilizar ferramentas como videoconferência e grupos de discussão virtual para manter a rede viva." 


\section{O que é o Open Space Technology}

O Open Space Technology (Tecnologia do Espaço Aberto), metodologia utilizada no fórum, vem sendo aplicado, em todo o mundo, tanto para reuniões de cinco pessoas como para encontros com dois mil participantes. Ele busca conferir a maior liberdade possível para que os participantes se organizem por si próprios, falem o mais abertamente possível - como se estivessem em um coffee break - e procurem envolver-se na solução da questão proposta.

"As pessoas gostam quando confiamos nelas. É importante transmitir essa confiança e, a partir disso, elas tomarão iniciativa", afirma Diane Gibeault, que atua há dez anos com essa metodologia.

Os participantes sentam-se em círculo. "O círculo não tem início, nem fim. Ele nos lembra de que todos estão nele como iguais", explica Diane.

Os princípios do OST são simples. No fórum, eles foram colocados da seguinte forma: "quem vier é a pessoa certa; o que quer que aconteça é a única coisa que poderia ter acontecido; a hora certa de começar é a hora certa; e quando acabar, acabou". Além disso, pelo "princípio dos dois pés", os participantes eram encorajados a caminhar para outros grupos ou mesmo "dar um tempo para respirar" sem constrangimento.

Não há uma agenda pré-definida. Ela é criada pelos participantes na abertura da reunião. A única exigência, porém, é a existência de um tema significativo para todos. O convite ao encontro deve trazer uma "lição de casa" prévia: preparar as idéias sobre o tema. No encontro, ele foi "Qual a liderança que eu preciso para favorecer o aprendizado, a inovação e a cooperação no serviço público?”. A partir dele, surgiram 19 tópicos, afixados em painéis, formando o "mercado de informação", por meio dos quais os participantes puderam escolher os assuntos que queriam discutir e verificar o local e horário deles.

As discussões, sugestões e ações dos grupos eram anotadas pelo responsável pelo tópico e, ao final das reuniões, repassadas à "sala de notícias" para a elaboração do relatório, cuja versão final foi entregue aos participantes antes mesmo de suas partidas.

Ao final, há um momento de convergência com a formação de um outro "mercado", no qual os interesses dos participantes são compartilhados de forma ordenada.

O fórum "Aprender, inovar e cooperar: uma conversa entre pares", que aconteceu nos dias 5 a 7 de junho, fez parte das comemorações de 20 anos da criação da ENAP e foi desenvolvido no âmbito do projeto de transferência tecnológica entre a ENAP e a CSPS, patrocinado pela Canadian International Development Agency (Cida), com apoio da Agência Espanhola de Cooperação Internacional (Aeci), da União Européia (Projeto EuroBrasil 2000) e do governo francês.
Tópico: Estabelecendo objetivos especificos, mensuráveis, alcançáveis, realistas e tempestivos para as organizações do serviço público

"Estabelecer objetivos específicos, mensuráveis, alcançáveis, realistas e tempestivos e alinhar a equipe a eles é uma dimensão importante da liderança e uma competência que desejamos de um líder do setor público. Sem isso, podem se formar líderes que não oferecem orientação suficiente para suas equipes sobre o que se espera deles em termos de resultados."

Tópico: Respeito à diversidade da (na) equipe

"A diversidade entre os membros da equipe é necessária e importante como 


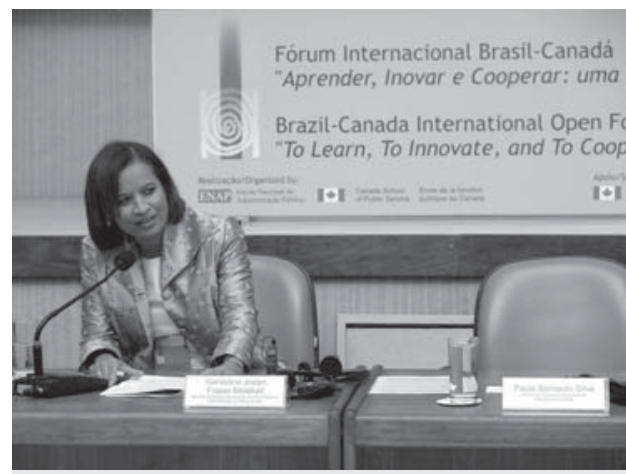

A ministra Geraldine Fraser-Moleketi

\section{“Inovação não deve ser considerada uma moda"}

A abertura do fórum contou com a presença do ministro do Planejamento, Paulo Bernando, e da ministra do Serviço Público e da Administração da África do Sul e vice-presidente do Comitê de Especialistas em Administração Pública da ONU, Geraldine FraserMoleketi, que proferiu a conferência inaugural. Em sua fala, a ministra ressaltou o papel dos dirigentes do setor público como catalisadores da mudança e da necessidade de que eles abriguem o processo de aprendizado, inovação e cooperação. "Muitos esforços de mudança são mal-sucedidos porque líderes não levam em conta as mudanças comportamentais subjacentes necessárias para que as pessoas se adaptem à nova realidade", disse. A seguir, trechos de sua exposição.

\section{Inovação}

"A inovação no governo e na administração pública não deve ser considerada uma moda ou uma tendência. É sempre arriscado, dentro daquilo que realizamos, procurar dar maior destaque a algum aspecto, o qual se torna algo 'da moda' e logo atinge o status de 'sabor do mês, do ano ou da década', até que uma outra tendência ocupe seu lugar. Os profissionais são seduzidos a abraçar com entusiasmo a novidade para não serem considerados ultrapassados ou obsoletos."

"Cabe destacar a importância do aprendizado e da gestão de conhecimento, bem como do monitoramento e da avaliação, enquanto se conduzem e se incubam as inovações e se aprende de iniciativas inovadoras. Devemos ter em conta, porém, o adágio 'não há quase nada de novo sob o sol', mesmo quando nos dedicamos a inovar."

\section{Liderança}

"A mobilização dos conhecimentos e habilidades em gestão e liderança não é apenas uma questão técnica visando a inovação ou a criatividade. O serviço público deve ser um espelho de uma sociedade que tem exemplos, metáforas, histórias de sucesso e vitórias sobre a passividade e o pessimismo. O serviço público deve ter uma cultura orientada para o serviço, que inspire as pessoas a aprender mais sobre conceitos e práticas de gestão, que serão, por sua vez, usadas para melhorar desempenhos fracos e a letargia. Para tanto, é necessária uma liderança tanto inovadora quanto decisiva, que irá inspirar confiança nos futuros dirigentes."

\section{Organização que aprende}

"Há uma interconexão entre inovação, gestão de mudança e, mais particularmente, a criação de uma organização que aprende. (...) Enquanto nos ocupamos em identificar as melhores práticas e inovações merecedoras de prêmios, devemos, ao mesmo tempo, analisálas e reinterpretá-las tendo como horizonte problemas maiores da política pública que existem em todo o sistema. Oportunidades de aprendizado também surgem de erros, se houver disposição para transformar fracasso em sucesso por meio da resolução de problemas e aprendizagem criativa. O serviço público deve aderir à ideologia da aprendizagem vitalícia e adotar os princípios da organização que aprende." 
forma de complementação de habilidades e competências."

"Possíveis desvantagens da diversidade são o surgimento de 'doutrinação’ e a acomodação, considerando que semelhante busca semelhante."

"Uma possível otimização seria investir em gestão por competência - com ênfase à CHA (competência/habilidade/ atitude) -, para 'preparar' adequadamente cada membro da equipe para suas atividades e responsabilidades."

Tópico: EAD - como manter alunos em cursos de e-learning

"É preciso uma ruptura com o paradigma da escola tradicional, que prestigia a disciplina do professor em detrimento da construção da autodisciplina. A desconstrução desse modelo tradicional é um processo de introjeção e modificação cultural que demanda tempo e experiência dos sujeitos do processo ensino/aprendizagem."

"Um elemento essencial do 'sucesso ou fracasso’ no processo de EAD é a figura do tutor. Ele não precisa ter o conhecimento absoluto do conteúdo, mas ter (conhecer) e manter (estimular) o foco no sujeito da aprendizagem. Destaca-se, nesse sentido, a importância da formação pedagógica do tutor - ele deve ser o motivador, a conexão, exercer sua liderança na troca de experiências."

\section{Tópico: Experimentar novas idéias}

"A inovação não é um ato único, mas um processo, que tem de ser liderado."

"É natural haver resistência à mudança causada pela introdução de uma nova idéia. Sua aceitação depende da motivação das pessoas envolvidas, que pode ser conseguida por meio de uma boa liderança. O líder também deve explicar o porquê da mudança pretendida."

Tópico: Mantendo e consolidando a motivação

“Mudanças na 'vida real' vêm forçando os servidores públicos a inovar. Um exemplo é a introdução do auxílio-maternidade, algo que não existia há 30, 40 anos. Essas inovações devem ser sustentadas porque a sociedade está mudando rapidamente (com ou sem a permissão dos servidores públicos!)."

"O mundo mudou para o tempoInternet, no qual se espera que as respostas sejam dadas velozmente... como isso impacta o mundo da burocracia?"

\section{Tópico: Formação e mudança}

"É difícil medir o impacto da formação sobre o processo de mudança da administração. Nesse sentido, uma recomendação seria basear a formação na pluridisciplinaridade de conhecimentos; na ênfase nas aptidões relacionais; no reconhecimento da importância da formação teórica, sem, no entanto, perder de vista que nada é mais importante do que a capacidade de colocá-la em prática; na ênfase na mobilidade transversal no desenvolvimento das carreiras, sem negar a importância da expertise setorial."

\section{Tópico: Educação e desenvolvimento humano}

"Quando a educação se transforma em ato de conscientização e desenvolvimento no mundo do trabalho, a 
dimensão técnica, sozinha, torna-se insuficiente. O desafio é desenvolver valores e atitudes."

\section{Mercado de cooperação}

No terceiro dia, os participantes foram chamados a fazer um balanço do encontro, respondendo a perguntas, em cartelas, sobre aprendizagem ("O que levo deste curso?") e inovação (“'O que pretendo fazer diferente em minha instituição?”).

Com relação à cooperação, cada dirigente foi solicitado a manifestar suas demandas, respondendo, também em cartelas, "O que a minha instituição gostaria de pedir" e "Que assuntos/temas/experiências eu gostaria de aprofundar"?, além de colocar as suas ofertas ("O que minha instituição pode oferecer ao grupo presente neste encontro?”).

Escritos os pedidos e as ofertas, era hora de procurar a instituição para a qual eles se dirigiam e afixar a cartela no painel dessa instituição. Estava formado o "mercado de cooperação".

\section{A difícil arte de liderar}

"Liderar é, em certa medida, desapontar a sua própria equipe até o ponto em que ela possa absorver". A definição do professor Marty Linsky, da Kennedy School of Government da Universidade de Harvard, nada lembra o ideal romântico de liderança, mas dá indícios das dificuldades a serem enfrentadas pelos líderes. Linsky lançou algumas reflexões provocativas sobre o exercício da liderança na conferência final do fórum.

Confunde-se algumas vezes, segundo Linsky, liderança com autoridade. Todos exercem, em sua atividade profissional, social ou familiar algum grau de autoridade. Da pessoa dela revestida, espera-se um conjunto de comportamentos já consagrados e o respeito aos limites do tamanho do poder concedido. Liderança, no entanto, significa desafiar esse limite e suportar as resistências resultantes disso. "A liderança cria tensões, gera resistências e recuos. O líder é um subversivo, na medida em que questiona valores, crenças e hábitos já consagrados e alimenta conflitos", diz. Se liderar fosse apenas distribuir boas notícias, seria uma tarefa fácil. Mas, longe disso, trata-se de distribuir perdas, desapontar, estressar a equipe.

O lado negro disso é que sempre haverá alguém tentando tirar o líder do jogo, o que torna o exercício de liderar, acima de tudo, uma atividade perigosa.

A liderança é dificultada pelo fato de que grande parte das questões que afligem as organizações não é de natureza técnica, mas adaptativa. O problema técnico pode ser resolvido com o conhecimento de um especialista ou de uma autoridade sênior. O problema adaptativo, porém, não consegue ser solucionado simplesmente

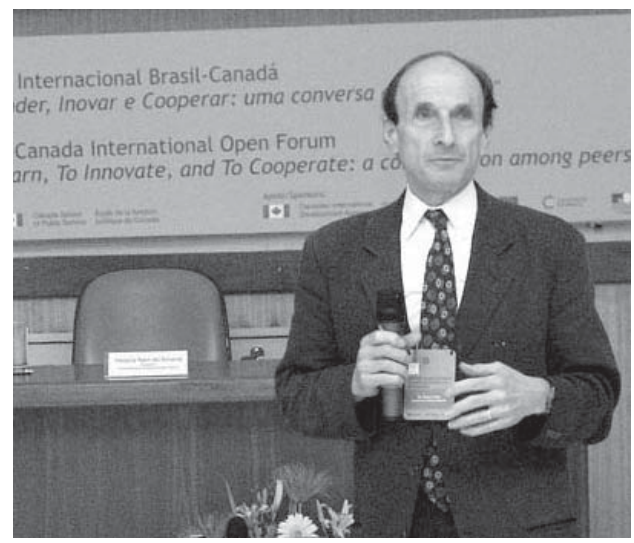

O professor Marty Linsky, da Universidade de Harvard

com o argumento lógico: ele demanda flexibilidade, aceitação de perdas e reconhecimento de que a solução está na mudança de comportamentos legitimados dentro daquela organização.

O professor de Harvard ressalta que o grande paradoxo é que, quando se quer que as pessoas não exerçam de fato a liderança 


\section{Manual de sobrevivência}

Liderar uma mudança adaptativa não é ter as respostas corretas, mas realizar intervenções efetivas em um sistema humano, em nome de um objetivo. Algumas dicas do professor Linsky:

Forme parcerias - dê ênfase aos relacionamentos pessoais e não apenas ao argumento lógico ou às evidências de sucesso. Liderar é uma tarefa política, o que implica motivar e mobilizar pessoas para a mudança;

Mantenha os oponentes por perto - relacione-se com os oponentes, mostre-lhes empatia. Eles não estão errados, apenas têm mais a perder e é com eles que o líder deve passar mais tempo;

Esteja consciente das perdas - se um jogo resulta em "ganha-ganha", significa que nenhuma mudança muito significativa irá acontecer. Ajude as pessoas a lidarem com as questões mais difíceis, que exigem admitir perdas.
Tenha em mente que lhes pedir para realizar tarefas adaptativas é pedir muito. O trabalho adaptativo requer, em certa medida, deslealdade a valores enraizados. Mostrelhes, como líder, que você tem consciência do que está pedindo para abrirem mão;

Cuide-se! - liderar é uma tarefa solitária, mesmo que tenhamos feito parcerias. Faça a distinção entre você como pessoa e seu papel de líder. Arranje um tempo e um espaço para reflexão e para lembrá-lo do sentido e do objetivo de suas ações. Encontre alguém, de preferência de fora da organização, para confidenciar seus problemas, sem ser julgado ou correr risco de ser traído.

Fontes: HeifeTz, Ronald; Linsky, Marty. A survival guide for leader. Harvard Business Review, June, 2002. Dos mesmos autores: Leading with an open heart. Leader to leader, 26, 2002 (fall) e When leadership spells danger. Leading in tough times, vol. 61, n' 7, April 2004.

- ou seja, não criem dificuldades, nem levantem questões difíceis que desafiam valores e crenças -, as organizações promovem-nas e passam a chamá-las de "líderes".

\section{Aceitar ser parte do problema}

Se há um problema na organização, a responsabilidade tem de ser dividida também com o líder: ou este participou de sua criação ou, no mínimo, é parte da razão pela qual a questão ainda não foi atacada. Não admitir essa responsabilidade é negar que o próprio líder também precisa mudar, o que retira a legitimidade de seu discurso de mudança.

Identificado o problema, ele deve ser lançado para o centro da mesa de discussão. "O problema tem de deixar de ser o elefante de quatro toneladas que todos vêem, mas sobre o qual ninguém quer falar", diz Linsky. Nesse sentido, é fundamental que o líder seja um empreendedor: assumir riscos, confiar em seu julgamento e colocá-lo em prática fazem parte de sua jornada.

Liderar, além disso, é a arte da improvisação, não há um script a ser seguido. $\mathrm{O}$ líder tem de dar respostas no momento em que as coisas estão acontecendo. No entanto, é essencial que ele se distancie da situação, "saia da pista de dança para ir à sacada", para perguntar-se o que realmente está se sucedendo.

O professor lançou três desafios para o ensino da liderança aos servidores públicos.

Desafio 1 - Como preparar seus alunos para um mundo cada vez mais incerto e 
caótico -, no qual a mudança é a regra e a adaptabilidade é uma habilidade crítica para o sucesso e a sobrevivência -, a menos que a sua escola trabalhe dessa forma e seus cursos sejam aproveitados dessa maneira? A sua escola tem uma cultura de liderança? No papel de professor ou de administrador, você espelha o seu comportamento de liderança? Qual a diferença entre ensinar liderança e ensinar outras disciplinas que serão úteis para os servidores públicos de hoje e para os que virão?

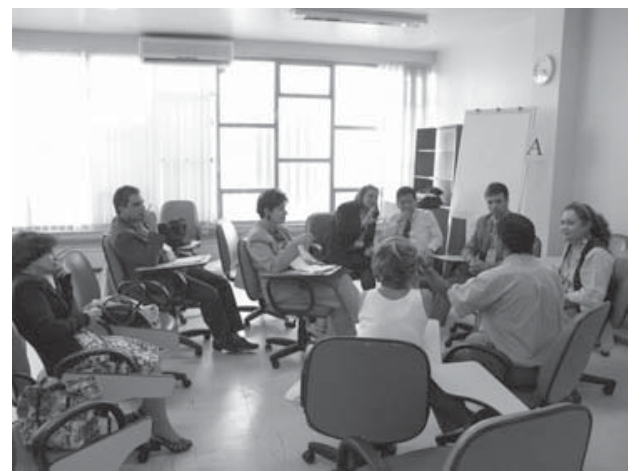

Um dos 19 grupos de discussão formados

"No ensino de liderança, o professor tem de espelhar o comportamento de liderança que ele procura criar nos alunos. Cada classe é um caso diferente de liderança. Supõe-se que os professores, como toda figura revestida de autoridade, conheçam todas as respostas. Não é o que ocorre aqui. Ensinar liderança como uma arte experimental desafia as expectativas dos alunos e será desorientador tanto para estes quanto para os próprios professores. A liderança, diferentemente da gestão, é uma atividade subversiva, motivo pelo qual vemos tão pouco disso em organizações grandes que prezam o dever e a lealdade."

Desafio 2 - Você realmente quer assumir a responsabilidade de preparar pessoas para liderar a mudança, quando é muito mais seguro treinar pessoas para serem zelosas, competentes e gerentes "criativos dentro dos limites"?

"A realidade é que, se você resolver ir adiante com isso, não poderá controlar os resultados e, sendo bom naquilo que the é previsto realizar, você poderá não aprovar todas as conseqüencias. Pense bem antes de comprometer-se."

Desafio 3 - Em qualquer sistema humano, por definição, cada membro é parte do problema. Qual é a sua parte na "bagunça" que você está tentando arrumar? De que forma você irá mudar o seu próprio comportamento ou os seus próprios valores para progredir? Qual é o seu desafio adaptativo? Dentre tudo o que você valoriza, o que você está disposto a abrir mão? 